\title{
Post Occupancy Evaluation towards Indoor Environment Improvement in Malaysia's Office Buildings
}

\author{
Natasha Khalil \& Husrul Nizam Husin \\ Department of Quantity Surveying, Faculty of Architecture, Planning \& Surveying \\ University Technology of MARA Perak, Malaysia
}

Tel: 60-5-374-2000_E-mail: natas582@perak.uitm.edu.my, husrul820@perak.uitm.edu.my

\begin{abstract}
The indoor environmental factors considered in office building must be determined in order to meet user's requirement. Disruption of indoor environment may constitute to reduce occupants' efficiency and work productivity. Therefore, Post-occupancy Evaluation (POE) is a prominent tool that able to indicate satisfaction and comfort level needs by building occupants as lessons learned to identify problems in indoor environment. By using occupants as benchmark of evaluation, the potential of improving the indoor environment in buildings is enormous. With relation to the title, the main purpose of this study is to provide recommendation to improve quality of indoor environment in office building, by analytical study on the level of effort and phases of conducting POE and determining occupant's satisfaction level. The survey used in conjunction with physical measurements to determine how environmental factors affect occupants' perceived comfort and productivity levels, and a benchmarking example of using the survey to establish how new buildings are meeting a client's design objectives. It is recommended that the application of POE is prioritized as strategic level decision making and emphasized as continuous activity in environmental evaluation.
\end{abstract}

Keywords: Post Occupancy Evaluation, Office Buildings, Indoor Environment, Comfort Level

\section{Introduction}

In the current situation where people concerns about sustainability environment, building occupants seek to obtain comfort and efficiency in their office. Occupants demand to have priority in terms of comfortability to use and utilize the facilities and services as it must be fit for purpose of the user. Work productivity of workers may be demotivated and interrupted due to poor environmental conditions. The question is, how to ensure that the indoor environment of the building is met the user's satisfaction? Is the building element and facilities fit for the user's purpose and well function? Post Occupancy Evaluation (POE) is one of strategic implementation of analysis on building sustainability after occupancy. POE has been defined by Zimring and Reizenstein (1980) as examination of the effectiveness for human users of occupied design environment.

POE systematically analyses a particular environment to gain understanding of the impact it as on occupants of a building and its environment, hence how it facilitates or inhibits daily activities of the occupants. Information of the building's condition is gained by reviewing what the occupants' feel and how they response to their needs by use and occupy the building. Among the benefits gathered from POE is it helps to identify successful design features to repeat (Watson,2003), identify problems to mitigate or reduce, improve building environment and performance (Vischer,2002; Hewitt et. al, 2005), fine tune completed buildings, identify redundant or unnecessary building features, empower users to negotiate building issues and others.

Sekhar, Tham \& Cheong (2002) pointed that occupant surveys and interviews with the building manager would provide additional information, which represent the evaluation of the users of the building. This paper is therefore purposely to determine occupants' satisfaction in terms of indoor environment, namely i) level of cleanliness, ii) visual comfort, iii) thermal comfort, iv) air movement, and v) noise pollution. This study is limited to the building occupants in one building only.

\section{Problem Statement}

The climate of Malaysia referring to Yuan (1987) can be classified as warm-humid equatorial, characterized by high temperatures and humidity. Air temperature averages within 22 and 32 degree Celsius with small annual and diurnal ranges. It is continually near but seldom exceeds normal skin temperature. The location of Malaysia which is under tropical climate region is naturally hot and a humid climate. Seeing this situation, majority of office buildings in Malaysia served air-conditioning and mechanical ventilation systems to maintain a thermally comfortable indoor environment. Rapid development of office building which is normally located in the city area incorporates issues in 
terms of cleanliness, noise and air pollution. According to Cheong and Chong (2001), the provision of comfortable indoor environment for the occupants is the only aspect in achieving better indoor air quality. Chemical pollutants, volatile organic compound, noise pollution or pollutant contaminants are among of factors that can have impact on the quality of indoor environment. Pollutant emissions from human activities, building materials, air handling units, etc. in the form of both living and dead material take place continuously in any type of buildings.

Over the last 20 years, a range of POE methods have been developed and their systematic application has demonstrated a huge potential not only to reduce the financial and environmental costs, but also to improve the quality of life, comfort and productivity of building (Nicol and Roaf, 2005). All these factors place constraints on the ventilation design, and if this is poor, it can lead to the deterioration of indoor air quality, thermal comfort and disrupt work productivity of building user.

\section{Research Objectives}

The introduction and the problem statement above led to the formulation of the author's study objectives. The objectives for this study are:

i) To determine occupants' satisfaction and perception level in their office buildings; in terms of indoor environment i.e. thermal comfort, air movement, visual comfort, noise pollution and cleanliness.

ii) To suggest and recommend ways to improve office indoor environment

\section{Research Methodology}

Generally, there are 3 phases of methodology for this research. The first phase in doing this research is to define the area of study, the concept, approaches and scope of POE by review precedent research and literature review of POE. The problem identification is reviewed through various sources of literature, observation, study visits and unstructured interviews. The second phase is by analysis of survey by developing and distributing questionnaire to building occupants' in one sample office building. All collected data is analyzed to get findings of the research and to achieve the research objectives. After analysis being reviewed, the author suggests and recommends ways to improve the indoor building environment. In the third phase, the author concludes all findings and provides future study recommendation.

\section{Literature Review}

POE in the 1960s and 1970s involved in individual case studies of public and student housing sector (Vischer,2002; Zimring, Rashid \& Kampschroer,2000) in Britain, France, Canada and United States. The evaluation is primarily involved collecting information about occupants and building through questionnaires, interviews, site visits, and field observation. It was then widespread to other facilities such as army barracks, hospitals, prisons, courthouses and hospital. By seeing the logical step and beneficiary results from POE, it was later applied to commercial real estate and office buildings by the mid of 1980s. Information from POE has been used by the public agencies in support of the design criteria and guidelines. POE programmes are conducted by a number of project team after construction in order to identify lessons learned by analysis of findings.

POE are typically performed within 4 to 24 months following occupancy of a new or renovated facility and are performed only once for an individual building. However, Watson (2003) in his opinion states that POE can be conducted at any time in the life of a building and it is not necessary to conduct in between the time frame. In POE, occupants ask questions and also provide answers to design professionals. As the design is applied the occupants begin to understand the implications of the spaces and facilities they asked for. Designers get a view of what users need and what is important. The consequences from the evaluation able to presents other objectives like provide design consideration for environment improvement, reduce maintenance and operation costs. Figure 1 illustrates the indoor environment audit methodology that commence with an investigation of the issues and characteristics of the indoor environment.

A POE study conducted by Kavgic et. al (2007) at a theatre in Belrade, Montana is purposely to identify where improvements could typically be made based on the results of monitoring (temperature, relative humidity, air speed and heat flux) as well as the assessment of comfort and health as perceived by occupants. The study has shown that for most of the monitored period the environmental parameters were within the standard limits of thermal comfort and Indoor Act Quality (IAQ). Another survey conducted by Wagner et. al (2007) on workplace occupant satisfaction in 16 office buildings in Germany revealed that the occupants' control of the indoor climate and moreover the perceived effect of their intervention strongly influence their satisfaction with thermal indoor conditions. These precedent research has showed the significant contribution of POE result towards improving indoor environment not only to office buildings, but also to other type of buildings i.e. residential, schools, religious, commercial etc.

\subsection{Process of $P O E$}

Generally, there are three (3) phases and steps involved in conducting POE. The phases of POE process are namely, i) planning, ii) conducting and iii) applying. 
- Planning

During the planning, all preliminaries agendas such as objectives of conducting POE are defined. This is to ensure that POE is organized and initiate the process of evaluation. It also can be called as pre evaluation phase, where it determine feasibility study of a building, review and provide analysis of building performance, define the strength and weakness of the building and identify who are the building users or occupants. This is vital in establishing research plan before evaluation starts. Strategic levels then require to proposed manpower or resources to sense of the data in terms of the questions asked in the beginning of research.

\section{- Conducting}

Data collection is the key task in conducting POE. At this phase, the building users are identified in order to develop data collection; whether based on interviews or questionnaire. This phase is where the evaluation takes place and it is important to ensure that all data collection procedures are monitored and managed. After evaluation conducted, the data is analyzed. This involved the finding and making sense of the data in terms of the questions asked in the beginning of research.

\section{- Applying}

Application of POE involves reporting the findings, recommending and planning actions. The report finding depends on the purpose to conduct. The purpose could identify problem and unsuccessful performance in facilities. Reports findings are implemented, actions are taken and the effects of the actions are measured.

\section{Analysis and Findings}

The sample building is categorized under private office building which is located at the golden triangle area in Kuala Lumpur. There are 60 questionnaires distributed to the building occupants. All of occupants of the building were desk-based and the arrangement offered a mix of single occupancy rooms, low-occupancy open plan rooms and high-occupancy larger open plan rooms.

A self-administered questionnaire which format is based on Likert-Scale is prepared for the answers rate by the respondents. The Likert-Scale consists of 5 numerical nomenclatures indicating the responses given by the respondents on each question, which are ranging from " 1 " to " 5 ". Table 1 presents the result of satisfaction and perception level in terms of indoor environment in percentage composition.

Based on summary exhibits in table 1, majority of the respondents are in comfort level in terms of building cleanliness and noise pollution. However, the highest percentage indicated as uncomfortable environment in the office is in terms of cooling system $(73 \%)$, natural day lightings $(53 \%)$, provision of air movement $(40 \%)$ and also quality of indoor ventilation (47\%). In terms of occupants comfort level in the building unit, $40 \%$ of the respondents are in medium rating only (Figure 2). Majority of the respondents indicated that their work productivity is decreased due to poor indoor environmental, which constitute to $47 \%$ out of total respondents (Figure 3 ).

Based on the survey findings, it can be concluded that visual comfort, indoor air movement and ventilation constitute the highest factor in terms of occupants' comfortability. Therefore, the author recommends several ways to mitigate the problems associated with indoor environment in office buildings:

a)

Cooling system (Air Conditioning)

Allow staff to have control of the cooling temperature. The centralized cooling system should be replaced Allow staff to have control of the cooling
to split unit as the gross floor area is not very spacious.

b) Visual Comfort (Day Lightings)

- $\quad$ Provide day lightings integrated with electric lighting controls in several area provisions. For example, provision of atrium and curtain glass walls.

- Allocate larger and higher window openings to improve daylight penetration

- $\quad$ Provide view space facing outdoor environment and to perceive natural day light

c) Indoor Air Movement and Ventilation

- $\quad$ Provide $\mathrm{CO} 2$ sensor during periods of high occupancy whereby the $\mathrm{CO} 2$ sensor alerts the system to draw air from adjacent zones to increase fresh air ventilation

- $\quad$ Provide ventilation fans in the office common areas to regulate proper air circulation

- $\quad$ Provide moisture control to prevent bad smells to office common area

In general, quality of indoor environment in office buildings can be improved by:

- $\quad$ Use recyclable or renewable materials to avoid emission of chemical or microbial contaminants. For example, materials for furniture, finishes. 


$\begin{array}{ll}- & \text { Use environmentally-products } \\ \text { service } & \text { Public awareness to practice a healthy environment and promote more campaigns through community } \\ \text { - } & \text { Emphasize energy-efficient design in office buildings }\end{array}$

\section{Research Conclusion and Recommendations}

It can be concluded that POE provides significant impact on creating change in terms of improving building environment in two ways. Firstly, by providing lessons and feedback for the owner or those involved in the environment improvement works. They can lead towards enhanced quality of indoor environment by sensitivity to changing needs of occupants. Secondly, by empowering end-users as post-occupancy evaluation that provides benchmark and a pool of analysis to show how the end product i.e. the building design and its environment management, meets the needs of its client and users. By effective implementation of POE, it enables the relevant stakeholder to shorten the learning time about the positive and negative environment changes.

By providing opportunities for improvement of various stages of building processes, and of the relationships between environment and behavior among owners, users, and designers, POE endow significant role to play in the building industry. It is suggested that POE should be implemented as a real practice in Malaysia as benchmarking towards sustainable environment. Ideally, POE must be e a continuous activity to evaluate the performance of building in certain duration of time. Continuous programmes of POE not only able to identify problems constitute to disruption in building performance, but also able to avoid emergence of defect or deterioration. By providing lesson learned derived from application of POE, it should be incorporated in the early design phase and planning for any buildings. All construction players should prioritize the application of POE as strategic level decision making to maintain sustainable environment.

\section{References}

Cheong, K.W and Chong, K.Y. (2001). Development and application of an indoor air quality audit to an air-conditioned building in Singapore. Building and Environment. Vol. 36 pp 181-188.

Hewitt, D., Higgins, C., and Heatherly, P. (2005). A market-friendly Post Occupancy Evaluation:Building Performance Report. New Buildings Institute, Inc, Washington.

Kavgic, M., Mumovic, D, Stevanovic, Z. and Yound, A. (2007). Analysis of thermal comfort and indoor air quality in a mechanically ventilated theatre. Energy and Buildings. pp 1-10.

Nicol, F. and Roaf, S. (2005). Post Occupancy Evaluation and Field Studies of Thermal Comfort. Building Research and Information. 33(4), pp 338-346.

Sekhar, S.C., Tham, K.W. and Cheong, D. (2002). Ventilation characteristics of an air-conditioned office building in Singapore. Building and Environment. Vol 37, pp 241-255.

Vischer, J. (2002). Post Occupancy Evaluation: A Multifaced Tool for Building Improvement. Federal Facilities Council. US: The National Academy Press. Chapter 3 pp. 23-34.

Watson, C. (1996). Evolving Design for Changing Values And Ways Of Life. A Paper for IAPS 14 Conference in Stockholm. Evolving Environmental Ideals; Changing Ways of Life, Values And Design Practices.

Watson, C. (2003). Review of building quality using post occupancy evaluation. Journal of Programme Education Building. Vol. 35, pp. 1-5.

Wagner, A., Gossauer, E., Moosmann, C., Gropp, Th., and Leonhart, R. (2007). Thermal comfort and workplace occupant satisfaction - Results of field studies in German low energy office buildings. Energy and Buildings. Vol. $39 \mathrm{pp}$ 758-769.

Yuan, L.J. (1987). The Malay House: Rediscovering Malaysia's Indigenous Shelter System, Penang. Institute Masyarakat, Malaysia.

Zimring, C. and Reizenstein, J. E. (1980). Post-Occupancy Evaluation: An Overview in Environment and Behavior. Vol 12: pp 429-451.

Zimring, C., Rashid, M. and Kampschroer, K. (2000). Facility Performance Evaluation. In Lawrence Federal Green Construction Guide for Specifies. US: General Services Administration. 
Table 1. Result of Satisfaction and Perception Survey from Occupants

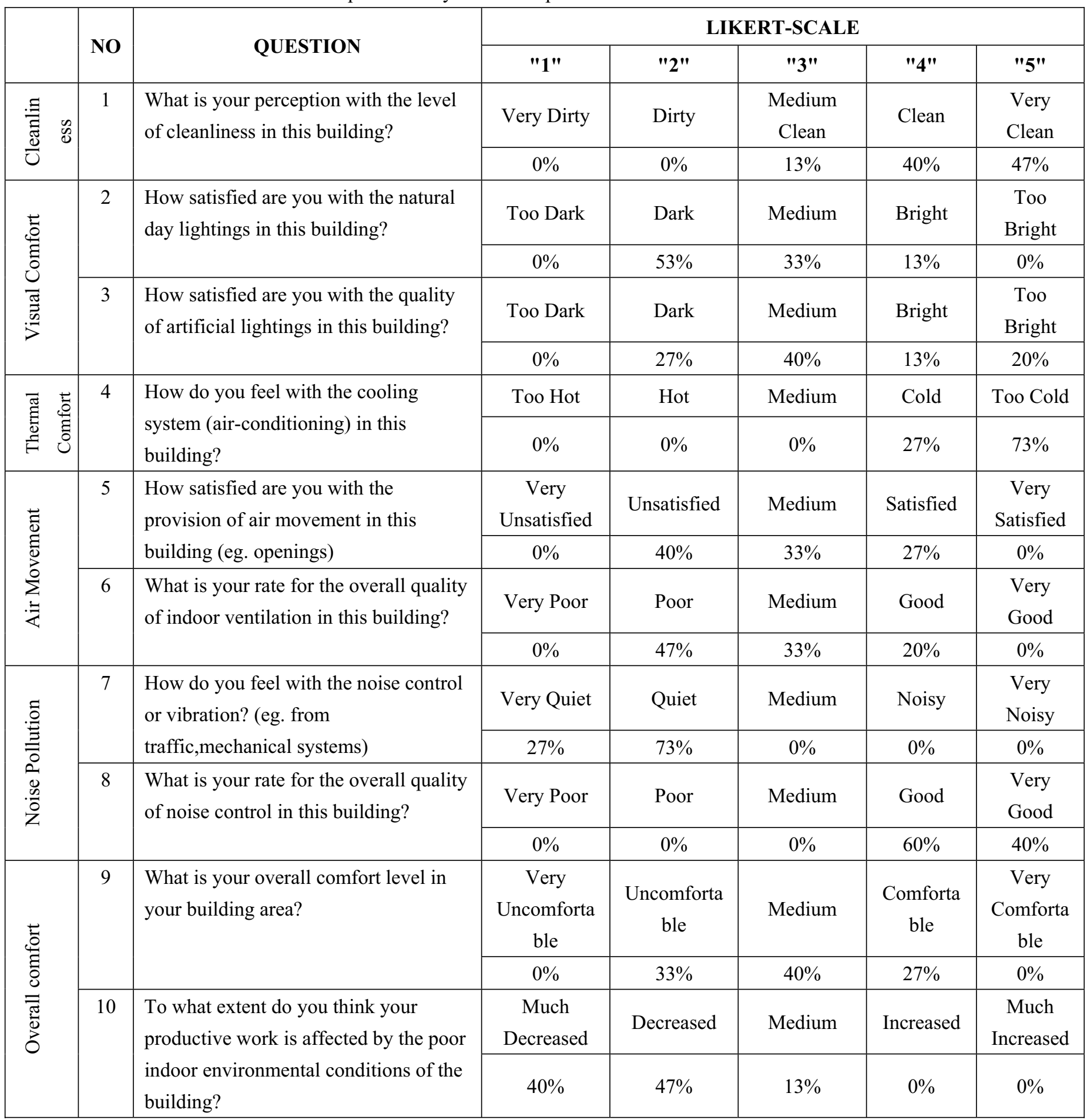




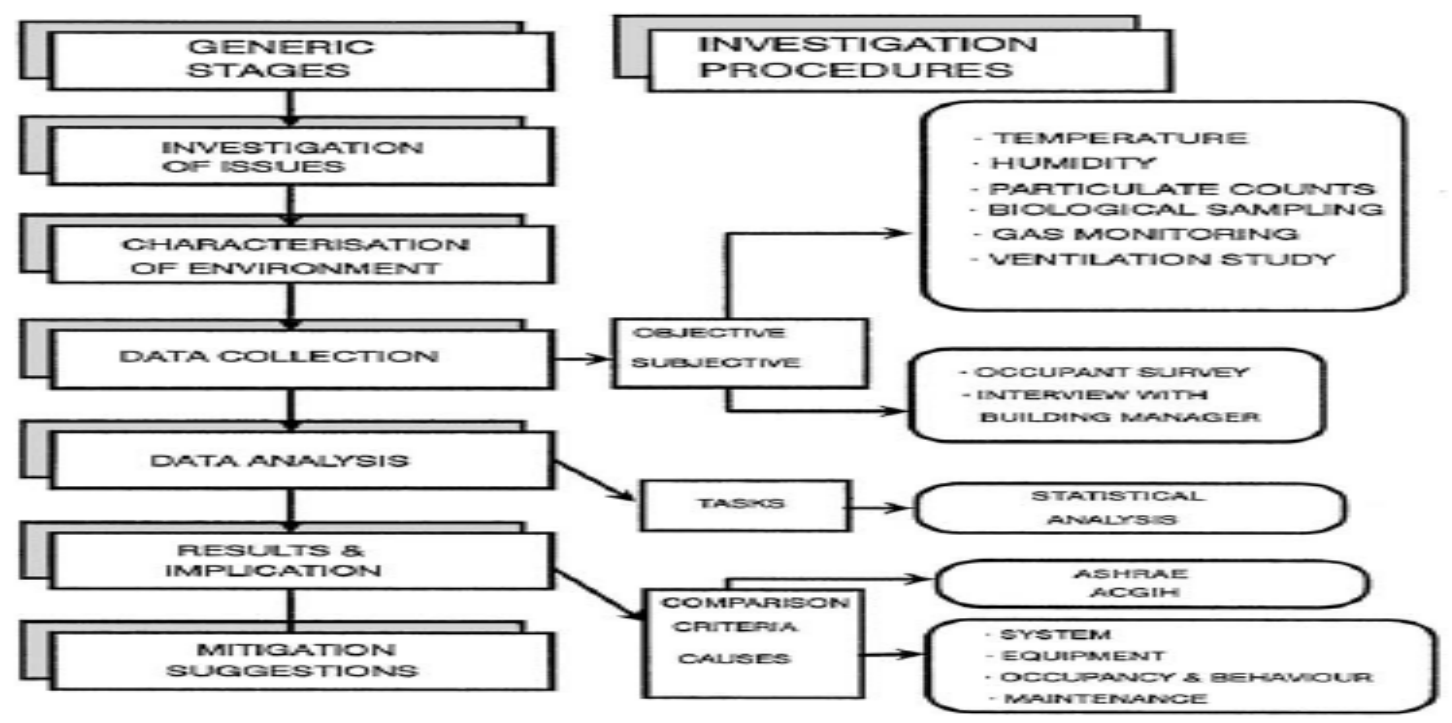

Figure 1. Indoor Environment Audit Methodology

(source: Sekhar, Tham \& Cheong, 2002)

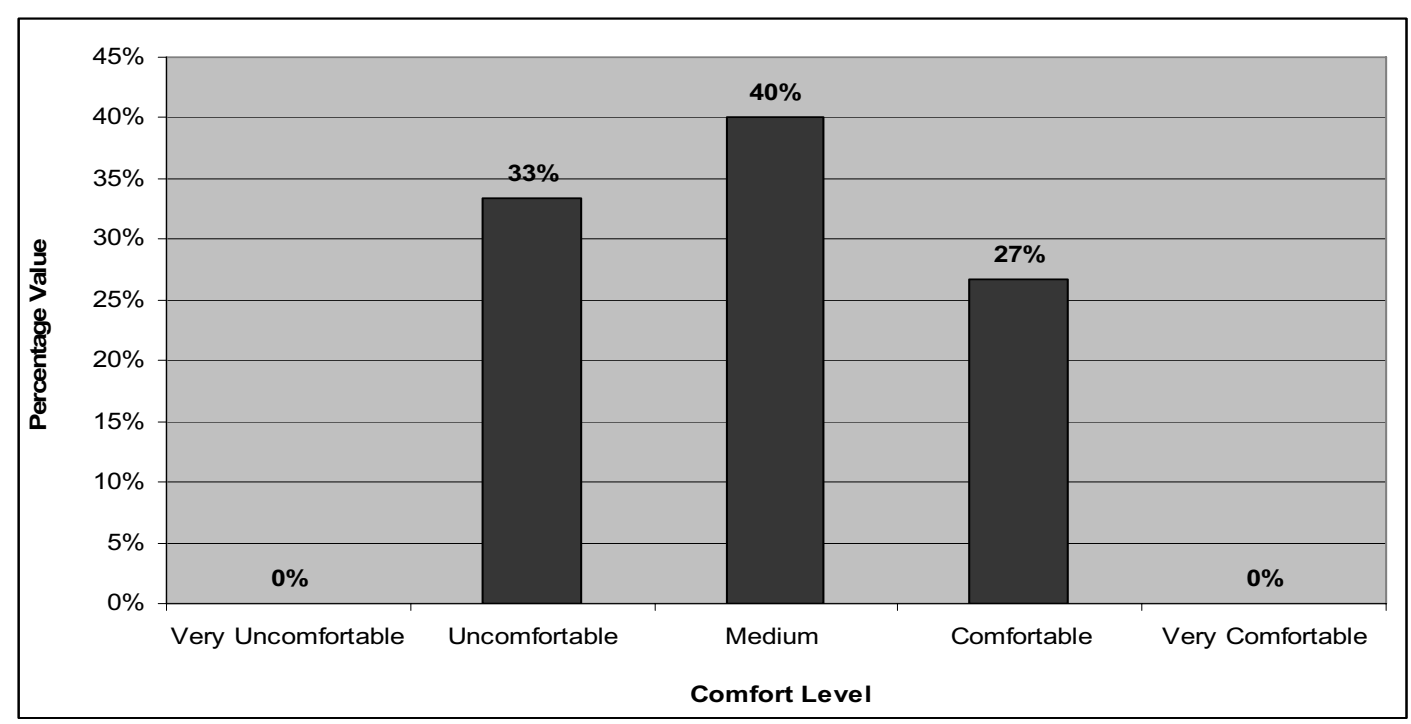

Figure 2. Assessment of Occupants' Comfort Level in Indoor Environment

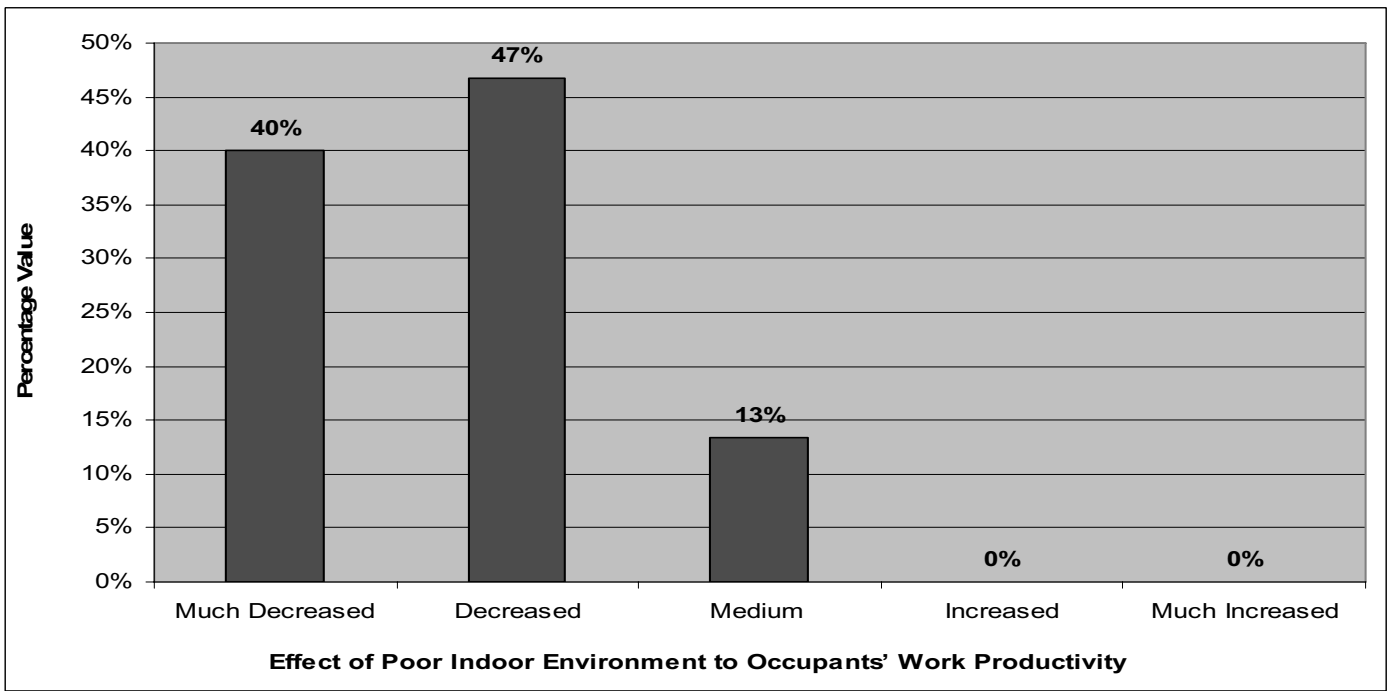

Figure 3. Assessment of Occupants' Work Productivity affected by Poor Indoor Environment 